\title{
Where have all the flowers gone? - Changing climate, seasons and weather and the challenges and opportunities for public health research
}

\author{
Neville Sweijda, Caradee Y Wright ${ }^{b, c}$ \\ ${ }^{a}$ Alliance for Collaboration on Climate and Earth Systems Science, Cape Town, South Africa. \\ ${ }^{b}$ Environment and Health Research Unit, South African Medical Research Council, Pretoria, South Africa. \\ 'Department of Geography, Geoinformatics and Meteorology, Pretoria, South Africa. \\ *Corresponding author, email: nsweijd@access.ac.za
}

Since the United Nations Framework Convention on Climate Change (UNFCCC) negotiations produced the Paris Agreement ${ }^{1}$ of December 2015, despite its subsequent notorious political challenges, the zeitgeist of global warming and subsequent climate change (GWCC) concerns has moved on from debating its very existence, toward understanding the way in which GWCC is and will manifest now and in the future. Any dispute regarding the attribution of global warming, and the consequences of climate change, to industrial-era emissions of greenhouse gasses emanating from anthropogenic origins, is now in the realm of 'Flat-Earthers'. The more relevant questions are now about how we rehabilitate the worldwide fossil fuel addiction (mitigation) and how we respond to the impacts of GWCC (adaptation).

That this first existential phase of the GWCC battle is complete does not mean that the role of the basic science is over. On the contrary. Enter "attribution science" or "fingerprint studies". We need to remain cognisant that GWCC is not the only driver of environmental change or the socio-ecological-economic impacts of environmental extremes. The record temperatures of the 2018 boreal summer have been blamed for a substantial number of deaths - ostensibly 65 people in Japan during a single heat wave event ${ }^{2}$ - and resulted in wild-fires of awesome proportions across the northern Hemisphere (Figure 1). Even suicide rates $^{3}$ have been linked to incremental increases in summer temperatures. The debate now is what proportion of the magnitude of these events can be attributed to climate change (and the consequences of its oceanic manifestation, such as the slowdown of the Atlantic Meridional Overturning Circulation) ${ }^{4}$ and how much to anomalous, yet quite normal, variability in weather systems. The challenge, still, is to distinguish between the impacts of trends genuinely emanating from Anthropocenealtered climate (whose existence is not in dispute) from what may be underlying earth system dynamics, or possibly the effect of increasing socio-political vulnerability, i.e. poverty and urbanisation, and infrastructural damage caused by "more built in harm's way". Furthermore, how do we tease out the impacts of a combination of these effects? Attribution matters because it determines what we do in response - for example, how much we should invest in mitigation (to try to reverse the effect) and how much we should invest in adaptation (to deal with the impacts).
Technically, the fêted Keeling curve, ${ }^{5}$ which started us thinking about the implications of increasing atmospheric carbon dioxide $\left(\mathrm{CO}_{2}\right)$ concentrations, focused on the overall upwardly trending global annual average, albeit that the Earth's boreal spring inhalation of atmospheric $\mathrm{CO}_{2}$ (i.e. northern hemisphere greening) is represented in it by the sub-annual dips. Until relatively recently we have been collectively concerned about how the changing climate will impact on the socio-ecological environment and on social and economic systems, on the basis of incremental changes to annual averages of amplitude and (re) distribution of climate features such as rainfall, temperature and others.

Now we need to urgently address how GWCC manifests in the respective components of the Earth System and in particular, in sectors of society and the economy, at a range of other time and space scales - especially in relation to the seasons. In other words, we are clear that climate is and will be changing; the question is, how does it change at scales that are more relevant to social systems and operations? This is at the interface between climate and weather, given that climate is merely the average of typical weather. An important scientific consideration of GWCC is understanding that it does not manifest on average and in general, but rather, the impacts range in magnitude through space and time. Even in the worst climate change scenario, we still have winter and summer. What matters is what these typical seasons of the future will be like and how extreme the extremes will be relative to what we are currently adapted to. We need to ask, which month or week will now correspond to the onset of the season and which will be the last; what will happen to the shoulder seasons, namely autumn and spring, and how will these changes differ in varying climate zones? Will different adjacent climate zones merge into one thereby reducing climate zone diversity? In traditional summer rainfall regions, for instance, will there be more or less rain than we get typically now, is it likely to rain more intensely for a shorter period than is typical currently, and will there be a longer dry season? What will happen to minimum temperatures in winter; will it still get as cold as we, and say, mosquitos, are well adapted to cope with or perhaps even colder than we are accustomed to? Are the perturbations to typical climate patterns (for example June-July- 


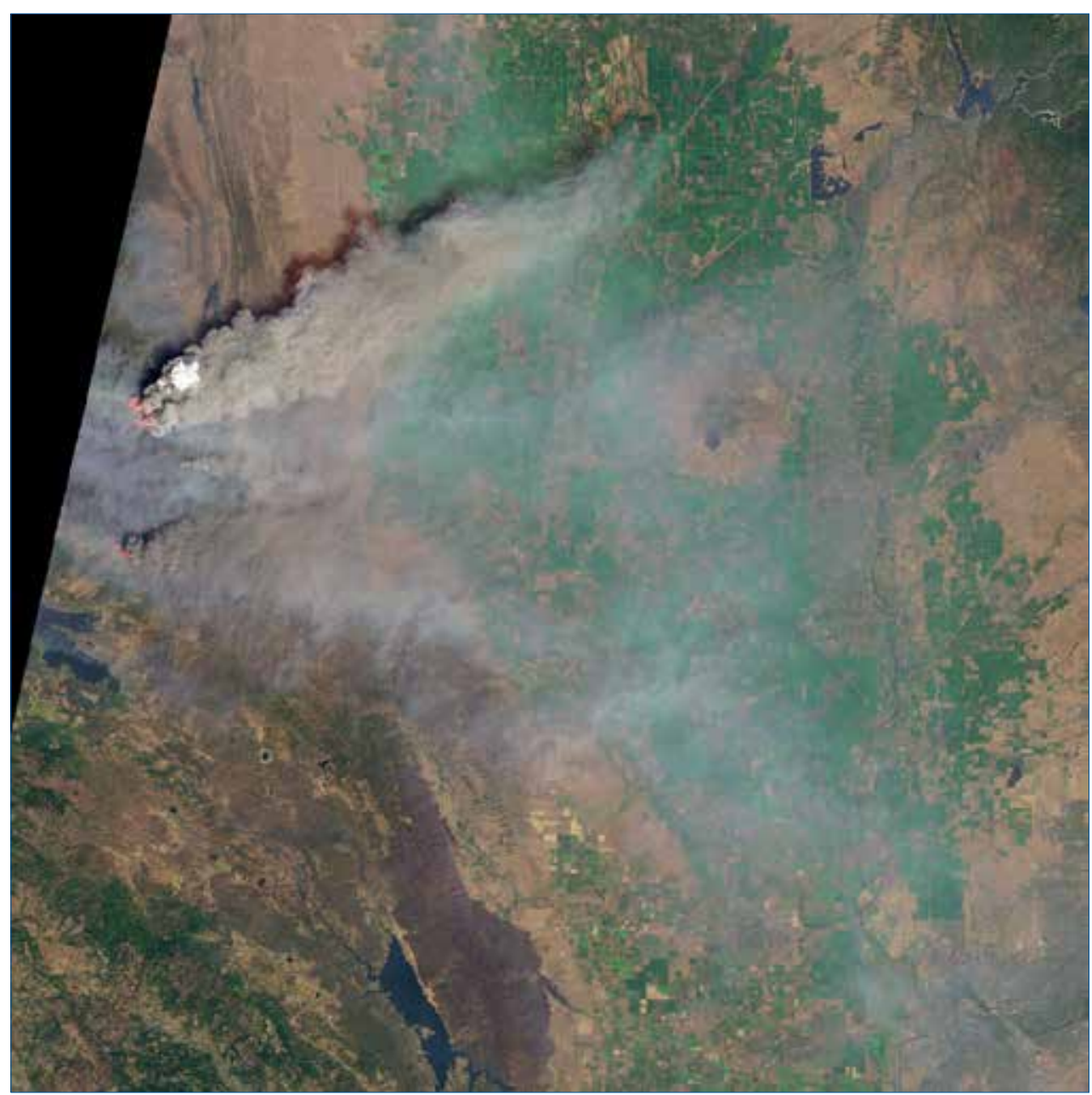

Figure 1. Composite image from the west coast of the United States in July 2018. One of the wildfires, the Mendocino Complex, became the largest fire on record in California. As of August 7, 2018 (when the fire was still burning), it had burned 1,200 km².

Source: https://www.nasa.gov/mission_pages/fires/main/index.html

August winter rainfall deficits in the Western Cape from 2015 to 2017) a result of a GWCC trend or part of a system driven by other undiscovered forces? This issue, i.e. the 'changing seasons' (see Santer et al, 2018) ${ }^{6}$ is the new frontier which the Alliance for Climate and Earth Systems Science (ACCESS) Programme has adopted as its research theme. It is postulated that we can expect more frequent and intense extreme weather events in the future ${ }^{7}$ - these are not only likely to have direct effects on human health, but disruptions of and trends in ecosystem structure and function, emanating from the disaggregation of phenological ${ }^{8}$ relationships (i.e. the timing of the lifecycle stages of interdependent organisms that are critical to ecosystem function) will also have consequences for infectious diseases. Changing ecosystems impact on the quantity and rate of the provision of a set of ecosystem goods and services that indirectly impact on human health and wellbeing (food production among them). Globally there are now examples of the collapse and transformation of several established and important ecosystems which have been attributed to just a small number of extreme weather events. ${ }^{9}$

The human health implications of the changes discussed above are self-evident and the broader medical health community has recognised this. ${ }^{10}$ The South African National Department of Health has recently appointed a Deputy Director in Environmental Health responsible for climate change, vector control and air quality. At the global Adaptation Futures conference held in Cape Town in April 2018, there were several sessions dedicated to a range of aspects of climate (change) and health impacts and actions. Also, the Public Health Association of South Africa has convened a Special Interest Group and the American Geophysical Union is organising a "climate-andhealth-research" special session at the Fall Meeting in 2018. Still, a lot of work remains to be done to ensure that action in respect of the public health impacts of GWCC is strategically driven, as it is likely that they will emerge among the biggest challenges of all the envisaged GWCC impacts.

It should be noted that there are some important research projects already at advanced stages of implementation in respect of GWCC impacts on human health in southern Africa. Among these is a project that focuses on selected infectious diseases which have a large climate-mediated component influencing prevalence and incidence. Most infectious diseases that have a seasonal prevalence or seasonal peak incidence, e.g. malaria, pneumonia, diarrhoeal diseases, are climate-mediated, so what is important to learn is how seasonal variability, including perturbations such as the El Nińo Southern Oscillation, ${ }^{11}$ and 
seasonal climate trends, are impacting on their prevalence. This is the new opportunity offered by GWCC for public health research - it brings a new set of skills from multiple disciplines together. There are new tools available such as the Variable Resolution Earth Systems Model (VRESM), ${ }^{12}$ the first African-coupled earth systems model, and a range of Seasonal Climate Forecasting ${ }^{13}$ systems. By characterising the relationships between infectious disease incidence and climate variability, these tools can be employed to make robust predictions of the likelihood of outbreaks, i.e. above average incidence, and trends in prevalence in specific climate zones, at time scales of weeks to months to decades ahead. This is the goal of the infectious Diseases Early Warning Systems (iDEWS) ${ }^{14}$ Project, which has developed such a system for predicting malaria outbreaks in Limpopo and is doing similar work for other infectious diseases. The project, a collaboration between South African and Japanese researchers, funded by Japanese International Cooperation Agency, Japan Agency for Medical Research and Development and the South African Department of Science and Technology, culminates in March 2019. Thereafter it is intended that an operational iDEWS Bureau will be set up as a joint venture between the South African Weather Services and the National Institute of Communicable Diseases. This is an important development and demonstrates that the climate science research and climate services communities, along with the public health and the medical fraternity are indeed taking concrete actions to prepare for the inevitable impacts of GWCC on public health.

\section{References}

1. United Nations Framework Convention on Climate Change. The Paris Agreement. 3 July 2018 [cited Aug 20 2018]. Available from: https://unfccc.int/ process-and-meetings/the-paris-agreement/the-paris-agreement.

2. The Guardian. 'Unprecedented' Japan heatwave kills 65 people in a week. 24 July 2018 [cited Aug 20 2018]. Available from: https://www.theguardian.com/ world/2018/jul/24/unprecedented-japan-heatwave-kills-65-people-week
3. Burke $M$, Gonzalez $F$, Baylis $P$, et al. Higher temperatures increase suicide rates in the United States and Mexico. Nature Climate Change 2018;8:723-729 [cited Aug 20 2018]. Available from: https://www.nature.com/articles/s41558-018-0222-x

4. Scientific American. Slow-motion Ocean: Atlantic's circulation is weakest in 1,600 years. 11 April 2018 [cited Aug 20 2018]. Available from: https://www.scientificamerican.com/article/ slow-motion-ocean-atlantics-circulation-is-weakest-in-1-600-years/

5. Wikipedia. The Keeling Curve [Cited Aug 20 2018]. Available from: https:// en.wikipedia.org/wiki/Keeling_Curve

6. Santer $\mathrm{BD}, \mathrm{Po}$-Chedley $\mathrm{S}$, Zelinka MD, et al. Human influence on the seasonal cycle of tropospheric temperature. Science 2018;361:eaas8806 [cited Aug 20 2018]. Available from: http://science.sciencemag.org/content/361/6399/eaas880 6?ijkey=06f5da5623261ed6be8baacd7eaa81720c823a17\&keytype2=tf_ipsecsha

7. Intergovernment Panel on Climate Change. Working Groups 11: Impacts, Adaptation and Vulnerability. Section 9.5 Extreme Events and Weather Disasters [cited Aug 20 2018]. Available from: http://www.ipcc.ch/ipccreports/tar/wg2/ index.php?idp $=354$

8. Nature.com. Phenology [cited Aug 20 2018]. Available from: https://www.nature. com/subjects/phenology

9. Harris RMB, Beaumont LJ, Vance TR, et al. Biological responses to the press and pulse of climate trends and extreme events. Nature Climate Change 2018;8:579-587 [cited Aug 20 2018]. Available from: https://www.nature.com/ articles/s41558-018-0187-9.epdf?author_access_token=iAnWdzF8nglwSjS6W ZjIQtRgN0jAjWel9jnR3ZoTv0M0c_-6ZvaWXrnL2jFBT7Yw34Qy4vTMk1Pz30on gvDmduy-kjSa2n8SMnX3uTMrFZ8U0-y8wwKdoknAdWQUEMFydUOf9govISST8gxKn6agFw\%3D\%3D

10. Watts N, Amann M, Ayeb-Karlsson, et al. The Lancet Countdown on health and climate change: from 25 years of inaction to a global transformation for public health. The Lancet 2018;391:581-630 [cited Aug 20 2018]. Available from: https:// www.thelancet.com/journals/lancet/article/PIIS0140-6736(17)32464-9/abstract

11. South African Weather Service. What is el Nino, la Nina and the el Nino Southern Oscillation? [cited Aug 20 2018]. Available from: http://www.weathersa.co.za/ learning/climate-questions/33-what-is-el-nino-la-nina-and-the-el-ninosouthern-oscillation

12. CSIR. Developing an African-based Earth System Model [cited Aug 20 2018]. Available from: https://www.csir.co.za/ developing-african-based-earth-system-model

13. Seasonal Forecast Worx at the University of Pretoria. Seasonal Forecasts 7 August 2018 [cited Aug 20 2018]. Available at: https://www.up.ac.za/media/shared/106/ ZP_Resources/seasonal_forecast_worx_aug2018.zp159992.pdf

14. Japan Agency for Marine-Earth Science Technology. Development of an Infectious Diseases Early Warning System for Southern Africa incorporating Climate Predictions (iDEWS) [cited Aug 20 2018]. Available at: http://www. jamstec.go.jp/apl/i-dews/outline_en.html 